\title{
Chlorinated Ring Carcinogen
}

National Cancer Institute

\section{Source}

National Cancer Institute. Chlorinated Ring Carcinogen. NCI Thesaurus. Code C45410.

A cancer causing cyclic compound in which one or more hydrogen atoms attached to the cyclic carbon atoms are substituted for chloride atoms. Many of which are pesticides.

( $\mathrm{NCl05)}$ 